\title{
Article
}

\section{Establishing consensus of position- specific predictors for elite youth soccer in England}

Roberts, Simon J., McRobert, Allistair P., Lewis, Colin J. and Reeves, Matthew J.

Available at http://clok.uclan.ac.uk/26436/

Roberts, Simon J., McRobert, Allistair P., Lewis, Colin J. and Reeves, Matthew J. ORCID: 0000-0002-3903-2910 (2019) Establishing consensus of positionspecific predictors for elite youth soccer in England. Science and Medicine in Football, 3 (3). pp. 205-213. ISSN 2473-3938

It is advisable to refer to the publisher's version if you intend to cite from the work. http://dx.doi.org/10.1080/24733938.2019.1581369

For more information about UCLan's research in this area go to http://www.uclan.ac.uk/researchgroups/ and search for <name of research Group>.

For information about Research generally at UCLan please go to http://www.uclan.ac.uk/research/

All outputs in CLoK are protected by Intellectual Property Rights law, including Copyright law. Copyright, IPR and Moral Rights for the works on this site are retained by the individual authors and/or other copyright owners. Terms and conditions for use of this material are defined in the policies page.

\section{CLoK}

Central Lancashire online Knowledge www.clok.uclan.ac.uk

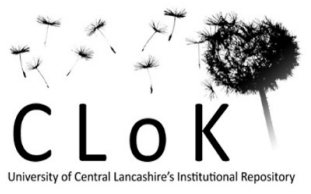


1 Title: Establishing consensus of position-specific predictors for elite youth soccer in England

\section{Abstract}

3 Purpose: To construct a valid and reliable methodology for the development of position4 specific predictors deemed appropriate for talent identification purposes within elite 5 youth soccer in England. Method: $N=10$ panel experts participated in a three-step 6 modified e-Delphi poll to generate consensus on a series of generic youth player 7 attributes. A follow up electronic survey completed by coaches, scouts and recruitment 8 staff $(n=99)$ ranked these attributes to specific player-positions. Results: A final list of 944 player attributes found consensus using the three-step modified e-Delphi poll. 10 Findings indicated that player-positional attributes considered most important at the 11 youth phase are more psychological and technical than physiological or anthropometric. 12 Despite 'hidden' attributes (e.g. coachability, flair, versatility, vision, etc.) finding 13 consensus on the e-Delphi poll, there was no evidence to support these traits when 14 associated with a specific playing position. Conclusion: For those practitioners 15 responsible for talent recruitment, our findings may provide greater understanding of the 16 multiple attributes required for some playing positions. However, further ecological research is required to assess the veracity of our claims. 


\section{Introduction}

Talent identification of youth soccer players is an important function of professional clubs in England and Wales and continues to receive research attention in the sport, exercise and pedagogic literature (Unnithan et al., 2012; Fenner, Iga \& Unnithan, 2016; Larkin \& Reeves, 2018). In the pursuit of this goal, the English Premier League introduced the Elite Player Performance Plan (EPPP) in an attempt to increase the number of players graduating from clubs who participate in the top four professional leagues in England (i.e. English Premier League, Championship, League 1 and League 2) (Towlson et al., 2017). Professional clubs in England and Wales annually invest between $£ 2.3$ and $£ 4.9$ million in their youth (i.e. U12 to U16 years: Premier League, 2011) talent identification and development environments (Tears, Chesterton \& Wijnbergen, 2018; Premier League, 2011). Such investiture in the academy infrastructure has seen an increase in the number of state-of-the-art, purpose-built facilities, all designed to support talented players' development and progression (Haugaasen, Toering, \& Jordet, 2014).

Despite this investment, however, evidence demonstrates that maintaining a place in an academy is challenging, with $\sim 90 \%$ of youth players in England and Wales failing to achieve full professional status (Anderson \& Miller, 2012).

Regarding previous talent identification research, studies have explored the skills and qualities that may discriminate between skilled and less-skilled youth soccer players. (Coutinho et al., 2016; Coelho e Silva et al., 2010; Vaeyens et al., 2006). For instance, skilled youth players tend to be heavier, taller (Coelho et al, 2010), and faster (Gil et al., 2014) than there less skilled counterparts. In a team sport such as soccer where body size, strength and power also contain advantages (Boone et al., 2012), the selection process has resulted in the overrepresentation of relatively older players due to advanced normative growth advantages around the time of age of peak height velocity (Cobley, Schorer, \& Baker, 2008; Philippaerts et al., 2006). 
Whilst these studies provide useful, informative data, the assumption that talented youth players can replicate features of peak adult performance appears to be flawed (Baker, Schorer \& Wattie, 2018; Vaeyens, et al., 2008). This predictive, early selection approach is problematic for a number of reasons: (i) talent identification and development is reported to be complex, multifaceted and non-linear with confounding elements such as growth and maturation which are difficult to control (Leyhr et al., 2018; Malina, 2008) and (ii) current performance does not always translate into future potential (Vaeyens et al., 2008; Unnithan et al., 2012).

Talent identification continues therefore to rely on subjective evaluations of players by recruitment staff (Christensen, 2009), and for those individuals responsible for identifying talented youth (i.e. talent scouts, academy coaches, recruitment staff, etc.) the job is complex, as no objective or valid indicator or measure of talent exists (Baker, Schorer, Wattie, 2018). This state of affairs was illustrated recently in a series of talent studies conducted in elite youth soccer environments in England, where the complex, and at times confused relationship between the organisational requirements, and the 'on the ground' work undertaken by recruitment staff was exposed (Reeves et al., 2018a; Reeves et al., 2018b; Larkin and Reeves, 2018). For instance, the multidimensional nature of talent in youth soccer can include prognostic dimensions such as 'physical abilities', 'fitness requirements', 'technical skills', 'perceptual-cognitive skills' and 'personal skills' (Murr et al., 2018; Vrljic \& Mallet, 2008). Due to the multifaceted nature of talent some have called for more objective predictors of future potential (i.e. Larkin \& O'Connor, 2017) or research designs that are in a position to infiltrate applied talent identification practice (Collins, MacNamara, \& Cruickshank, 2018).

Indeed, our recent talent identification work with talent scouts, heads of recruitment and academy coaches, provides some initial evidence to support this supposition. Using a verbal reporting protocol, we captured concurrent cognitions of recruitment staff during formal 
8111 v 11 competition (under 16s) at a professional English Premier League Academy. Content analysis of the concurrent verbal reports indicated that the recruitment staff openly disagreed about the skills and attributes required for identical playing positions. Furthermore, in a series of face-to-face follow up interviews, discrepancies between their own judgements and their club's recruitment philosophy were also captured (Lewis et al., in review).

Soccer is a team sport where each outfield playing position has role responsibilities that are both unique and common to other positions in the team (Murr et al., 2018). Due to the continuous, invasion-type nature of soccer, in a natural sequence of events players are required to act as either attackers or defenders depending upon the configuration of play (Gréhaigne, Richard \& Griffin, 2005). The rules of soccer do not constrain players to zones and so they are free to move up and down the field exploiting the width and depth of the playing area by creating or reducing space and time to achieve the game's primary objective (e.g. score or not concede goals). Despite previous attempts to establish a relationship between playing position and specific anthropometrical and fitness performance characteristics (Bidaurrazaga-Letona et al., 2015; Towlson et al., 2017) there currently appears to be no definitive agreement concerning position-specific differences and the attributes of youth players. For instance, Deprez et al., (2015) reported anthropometric, physical fitness and functional profile differences in 744 high-level soccer players aged $8-18$ years. Amongst the outfield positions defenders were observed to be taller than midfield and attacking players. Midfield players performed better on dribbling tests (U9 - U15) and exhibited superior endurance attributes. Attacking players were recorded as the most explosive, fastest and agile when compared to other outfield positions (Deprez et al., 2015). However, this study was unable to include other talent predictors such as training history, and bio-psycho-social factors considered to be as important in the talent identification process (Collins, MacNamara, \& Cruikshank, 2018). A later cross-sectional study reported the physical fitness characteristics of elite youth players in 
central versus lateral roles and found specific anthropometrical attributes such as relatively

107 older, mature, taller and heavier players selected for goalkeeping and central defensive

108 positions (Towlson et al., 2017). However, with the exception of Larkin and O'Connor (2017)

109 who aimed to understand generic attributes considered important for youth coaches at the entry

110 level of representative soccer in Australia, there is limited agreement on generic attributes when

111 associated with certain playing positions. Therefore, the specific aim of this study was to

112 propose a methodological framework for establishing position-specific attributes for talent

113 scouts and coaches involved in the talent identification and development process.

\section{Methods}

115 The position-specific consensus process featured a three-step modified e-Delphi method

116 (Meshkat et al., 2014) and online survey which took place between September 2017 and March

1172018 following full ethical approval from an Institutional Review Board in the United

118 Kingdom. The Delphi method, developed (primarily) by Dalkey and Helmer (1963) is an

119 iterative process that provides a process of acquiring consensus from experts where there is

120 little or no evidence and where opinion is considered important (Eubank et al., 2016). Initially,

121 a comprehensive list of generic attributes was identified and consensus was built from the

122 feedback provided by experts from the proceeding rounds. For the present study the modified

123 e-Delphi method consisted of three rounds of email questionnaires.

124 Panel selection

125 As our study required consensus of attributes in elite youth soccer, involvement from

126 recruitment staff, coaches, academy directors, coach educators and academics involved in

127 talent identification research was necessary. Despite no exact criterion for the selection of

128 Delphi participants available in the extant literature, it is considered important that panel 129 members are highly trained and competent within the area of specialist knowledge (Hsu, 2007).

130 Initial recruitment strategies for our panel included a presentation of our proposed body of 
131 research at the World Conference on Science and Soccer held in Rennes in April 2017 (i.e.

132 Reeves et al., 2018). Face-to-face meetings were then conducted with members of the Football

133 Association's (FA) talent identification department, before a series of final face-to-face

134 meetings were held with delegates and academics interested in researching talent in soccer at

135 the International Council for Coach Education (ICCE) conference held in Liverpool in July

1362017.

137 Interested participants were contacted further, on the basis of talent identification and

138 recruitment experience and expertise. As the aim of our study was to provide position-specific

139 predictors for talent scouts and coaches and since our aim was to also advance the evidence

140 base for talent identification in youth soccer, players were not included as panel members.

141 Following verbal agreement to participate, a letter of invitation was forwarded to each of our

142 panel members. The participants who agreed to be involved completed a written consent form

143 and provided an email address for correspondence purposes. Following receipt of written

144 consent, the aim of the project was explained. The final panel included the following members;

145 the Academy Director of an English Premier League club, talent identification staff at the

146 English Football Association $(n=2)$, head of player recruitment at an English Premier League

147 club and Championship club, Union of European Football Associations (UEFA) B licensed

148 coaches working in elite youth football in England $(n=4)$ and a professor of sport sciences

149 who specialises in researching and writing about talent identification in sport.

150 Generic attribute statements

151 For stage one of the study, we requested from our panel a list of generic attributes archetypal 152 of a talented youth soccer player. An open-ended text document with four categories: 'technical 153 attributes', 'physical attributes', 'psychological attributes', and a heading termed 'hidden 154 attributes' was forwarded to our panel. The first three headings (i.e. technical, physical, and 155 psychological) were adapted from the model of potential talent criteria by Williams and Reilly 
156 (2000). The term 'hidden' was adopted as this was a phrase commonly used by heads of

157 recruitment, academy coaches and talent scouts in a recent study (i.e. Reeves et al., 2018).

158 Other studies have adopted the term 'personal' (Jokuschies, Gut, \& Conzelmann, 2017) or

159 'social' (Williams \& Reilly, 2000). Panel members were invited to propose generic attribute

160 statements under the four headings and invited to provide a brief explanation for its inclusion.

161 The final list was compiled into a Microsoft Excel (2016) spreadsheet and reviewed by author

162 (3) who had worked previously as a professional youth soccer coach with an English League

163 club and author (4) who had worked as a performance analyst for an English Premier League

164 club. All the attributes were then compiled into a draft consensus document.

165 Round 1:

166

167 In the first round of the e-Delphi process the draft consensus document was forwarded to our 168 ten panel members. Each participant was requested to state how important each attribute was 169 using a nine-point scale (Meshkat et al., 2014). As with previous e-Delphi studies (i.e. Meshkat 170 et al., 2014) a score between 1-3 indicated that the panel disagreed with the attribute; 4-6 171 represented an attribute that was ambiguous; and 7-9 represented a statement that found 172 agreement. Attributes for which $70 \%$ of participants did not grade within the scale 7-9 were eliminated. The results were then distributed back to participants for round 2 .

174

175

176

177

Round 2:

The list of attributes that did not meet consensus from round 1 were forwarded to each panel member using the email address provided. Each participant was requested using the same ninepoint scale to grade the remaining statements eliminated at the end of round 1 . At the end of round 2 two new attributes were introduced by one of the panel members (i.e., 'coachability' and 'flair') these were accepted by the research team and included under the 'hidden attributes' category for round 3 .

\section{Round 3:}


184 During round 3, the participants graded the attributes using the same nine-point scale but with

185 the knowledge of the group scores from the previous two rounds. An identical procedure of

186 elimination was then performed and a final list of attributes was agreed.

187 Online survey

189 Following final consensus, the generic physical, psychological, technical, and hidden attributes

190 were then incorporated into a position-specific survey using an online survey tool

191 (https://www.onlinesurveys.ac.uk). Specific examples of each of the attributes was included

192 to avoid any potential confusion. The online survey was distributed using various social media

193 platforms (i.e. Facebook, Twitter, LinkedIn) for a period of four weeks. Specifically, on-line

194 communities considered relevant for talent identification in soccer (e.g. The Football

195 Collective, Professional Football Scouts Association) were targeted. The survey consisted of

196 two sections. The first of these included a series of demographic questions for each respondent

197 (i.e. age and gender, country of residence, coaching qualification and current job role). The

198 second section required each respondent to imagine they were responsible for talent

199 recruitment and using the generic attributes captured in the e-Delphi poll rank them according

200 to a recognised playing position.

For example, after selecting a recognised defensive position (e.g. central defender and/or full-back), midfield positions (e.g. central midfield, left midfield, right midfield) and/or attacking positions (e.g. wide attacking player and centre-forward), participants were asked to

204 select an attribute from the e-Delphi they thought was indicative of the position and rank using

205 a 7-point Likert scale. Attributes were ranked in order of importance from: $(7=$ most important; 1 = least important). The frequency of responses was recorded on a Microsoft Excel (2016) spreadsheet for each playing position and the overall mean score was determined by summing the item rank scores and dividing by the frequency of respondents to each question

209 (See Table 1 for an example). Therefore, higher values indicated higher levels of importance 
210 for each attribute and player-position. Due to the specialist nature of the position and the

211 specific coaching and talent identification routeway goalkeepers are not included in this

212 analysis.

Table 1 About Here

214 Results

215

$216 \quad e-D e l p h i$

217 Ten panel members with high levels of expertise and experience in the field of talent identification and player recruitment in elite youth soccer participated in three e-Delphi rounds. Following the first round 95 attributes did not reach full consensus. 31 of the original 126 attributes were accepted into the final list without modification. At the beginning of round two, 95 attributes that did not reach agreement were disseminated to the panel members. Following the second round of voting, agreement was reached on five positional attributes. Twenty-three attributes were omitted and 67 out of 95 attributes did not reach any consensus. During the third and final round, four attributes reached agreement. In addition, two new attributes were introduced and accepted. The panel also agreed to omit 61 attributes as they could not reach $70 \%$ agreement. The final list of physical, psychological, technical, and hidden player attributes that received full consensus from the e-Delphi poll are presented in Table 2. A breakdown of the full e-Delphi process and results is provided in Figure 1.

\section{Online survey}

During the four weeks that the survey was live (12 $2^{\text {th }}$ April $2018-10^{\text {th }}$ May 2018), a total of 99 participants registered their interest and fully completed the online survey. The majority of the participants were male $(n=88)$. All of the participants held a formal soccer coaching qualification which ranged from the UEFA A licence or equivalent, to the FA Level 2 in 
coaching soccer, or equivalent. None of our respondents indicated whether they had completed any formal talent identification awards (i.e. FA level 1 in talent identification: an introduction to scouting). The participants recorded a range of job roles within soccer which included; professional soccer academy managers, academy coaches who had responsibilities for player recruitment, participation coaches, coach educators and designated talent scouts. The respondents were located in various geographic locations around the world including; Europe $(n=81)$, Oceania $(n=13)$, North America $(n=4)$ and Asia $(n=1)$.

The descriptive statistics (mean \pm standard deviation) and rankings for the player positional requirements based on responses to physical, psychological, technical, and hidden attributes generated by the e-Delphi poll are provided in Table 3. Of note is the relative importance attached to perceptual-cognitive skills, with decision-making ranked highest for central defensive positions, central midfield positions, and left/right midfield positions. The importance of anticipation was ranked highest for central attacking and wide positions. Participants rated technical skills such as technique under pressure in congested areas of the pitch (i.e. central midfield and right/left midfield) as important. Tackling was recorded as most important for full-back positions with technical skills such as crossing and passing also highly rated. Interestingly, there were relatively low scores for physiological or anthropometric attributes. The highest recorded mean scores for physiological requirements included agility for right/left midfield positions, strength for central defensive positions, stamina for central midfield positions and speed for central/wide attacking positions.

\section{Discussion}

259 The aim of this study was to develop a robust methodology for the construction of player260 positional attributes, considered important for talent identification purposes in elite youth 261 soccer. This was accomplished by the implementation of a validated e-Delphi protocol 
262 (Meshkat et al., 2014) and an online survey. This paper, therefore, adds to previous research

263 (i.e. Larkin \& O’Connor, 2017) by providing a hierarchy of player attributes that are explicitly

264 linked to outfield positions. During our e-Delphi poll our panel members reported similar 265 generic attributes to those identified previously by Larkin and O'Connor (2017). However, 266 when the list of attributes was compiled into an online survey and linked to player position we 267 observed some interesting differences to that of our Australian colleagues. For instance, Larkin 268 and O'Connor (2017) rated a number of generic technical skills as most important (i.e. first touch, $1 \mathrm{v} 1$, and striking the ball). In the follow up interviews conducted as part of Larkin and

270 O'Connor's study, the justification for first touch as the most important attribute for players at 271 the U13 age group was because it was a considered to be a 'foundation skill' and a pre-requisite 272 for all on-the-ball actions. Whilst we do not disagree with this assumption, we too found literature on the importance of a player's first touch limited and so further work is required in this area. The same may be said for indicating whether the player was receiving the ball with their stronger or weaker foot and this may be worthy of further examination.

In contrast, our respondents ranked perceptual-cognitive skills such as decision-making in central defensive and midfield positions (i.e. central and right/left) and anticipation in attacking positions higher than any technical skills such as first-touch, passing or $1 \mathrm{v} 1$. Moreover, technical attributes were only considered most important when under pressure which supports Larkin \& O'Connor's (2017) point that further research is required to provide more ecologically valid assessments for assessing the technical abilities of young players.

\section{Perceptual-cognitive skills}

283 Previous soccer related research has consistently demonstrated that players with enhanced perceptual-cognitive skills (e.g., decision-making and anticipation), have a considerable advantage when compared to less-proficient players (Roca et al., 2011; Vaeyens et al., 2007). 
making are believed to be optimized when the training environment includes game-specific activities (O'Connor, Larkin \& Williams, 2017, Roca et al., 2012; Savelsbergh, Van Gastel, \& Van Kampen, 2010 Williams \& Ford, 2013). The quality of decision-making is often defined as the appropriateness of the decision preceding an appropriate action (O'Connor, Larkin \& Williams, 2017, Hohman, Obelöer Schlapkohl, \& Raab, 2016), and evidence of experts having superior visual search behaviour and fewer fixations to determine responses when compared to near-experts, or non-experts has been demonstrated in striking and fielding sports (i.e. cricket; McRobert et al., 2011) and invasion type sports such as a handball (Rabb \& Johnson, 2007) and field hockey (Elferink-Gemser, et al., 2007). Research surrounding how practice structure should be designed in order to promote the improvement of decision-making and anticipation in soccer has suggested practice should replicate the experiences a player encounters during competition (Patterson \& Lee, 2008; Vickers, 2007; Williams \& Ford, 2009). For instance, Ford et al. (2010) examined the differences between two types of practice activities structure - Training Form (TF) and Playing Form (PF) - in English youth soccer. While TF was defined as the type of activities that are based on technical and skill practices that did not contain game-specific elements (i.e. opposition); PF was defined as activities similar to the game-context incorporated through either small-sided games or phases-of-play. The results indicated that TF was predominantly used in the youth soccer sessions when compared to the PF. Despite this, several authors (i.e. Roca et al., 2012; Williams et al., 2012) have suggested that practices designed with a structure similar to the PF are beneficial to promote the development of decision-making and anticipation. This is supported by evidence that casual links exist between superior anticipation and decision-making skills for those players who experienced higher levels of soccer-specific play and practice hours during adolescence (Roca et al., 2013).

\section{Technical attributes}


312 Similar to Larkin and O'Connor (2017) our respondents rated the importance of technical

313 attributes such as tackling, heading, passing and crossing for defensive and midfield positions

314 and shooting, and $1 v 1$ for more attacking positions and technique under pressure. Clearly the

315 ability to distribute the ball effectively from one player to another in order for a team to

316 maintain possession is imperative, and there is evidence a positive association between time in

317 possession of the ball, and overall team success exists (Bradley et al., 2013). However, some

318 caution is required here as ball possession is multifaceted and influenced by factors such as the

319 playing style (Fernandez-Navarro et el. (2016), the quality of the opposition (Lago, 2009), the

320 score and the match location (Lago \& Martin, 2007). Passing was indicated to be an important

321 technical indicator for fullbacks. This has also been reported in high percentage ball possession

322 teams where defensive players performed better passing completions than offensive players

323 (Bradley et al., 2013).

324 An important technical attribute for midfield players was technique under pressure.

325 One might speculate that due to the often small, congested area where midfield players operate,

326 their ability to control the ball, pass, dribble and turn is performed while under a rapidly

327 changing environment with constraints on time and space (Vaeyens et al., 2006). This

328 particular attribute is an interesting one given that the interdependency of executing a technique

329 (i.e. passing) in an unpredictable, interactive environment could arguably be termed a

330 'technical skill' rather than 'technique' per se, due to the ability to adapt to different in-game

331 scenarios, and decision-making processes (Le Moal et al., 2014). For instance, previous

332 research has illustrated that when the proportion of attacking to defensive players in open-play

333 situations is constrained by numbers, time and space (i.e. 2 vs. 1,3 vs. 1,3 vs 2, 4 vs. 3 and 5

334 vs. 3) typically skilled youth players employ faster and more accurate decisions than their less-

335 skilled counterparts (Vaeyens et al., 2007a, 2007b). This has been attributed to more skilful

336 players employing a smaller number of fixations for longer periods in 2 versus 1 or 3 versus 1 
337

338

339

340

341

342

343

344

345

346

347

348

350

351

352

353

354

355

356

357

358

359

360

361

situation towards the ball or player in position of the ball. Whereas in situations where the number of attacking and defensive players is increased (i.e. 3 vs 2, 4 vs. 3, and 5 vs 3 ) skilled players employed a higher number of fixations for a shorter time period (Vaeyens et al., 2007a, 2007b). However, some have questioned the ecological validity of such skill-related performance tests as they are conducted independent of match context (Aquino et al., 2017).

\section{Physiological attributes}

Because soccer has movement demands such as walking, jogging, running, sprinting, and jumping, it was no surprise that eight physiological attributes found consensus in the e-Delphi process. However, the respondents in our survey only selected five of these (i.e. speed, stamina, strength, agility and acceleration) and when requested to associate these with specific player positions it was noticeable how physiological attributes recorded relatively lower mean scores when compared to tactical and technical attributes. Clearly, an emphasis on physiological requirements are important considerations when assessing talented youth players, and as such there are a battery of standardised tests which sports science and medicine staff employ as part of both a habitual training programme (Enright et al., 2018) and the EPPP requirement that periodic audits of player somatic maturation status are carried out (Towlson et al., 2017). For example, repeated sprint ability tests (Chaouchi et al., 2010), agility tests (Pojskic et al., 2018), vertical jump height (Acero et al., 2011) and the Yo-Yo intermittent recovery test 2 (Krustrup \& Bangsbo, 2001). However, due to the unpredictable nature of youth development (Bailey and Collins, 2013) some have questioned the relevance of such tests in the talent selection process (Carling \& Collins, 2014).

The importance of stamina was reported for midfield players but not for central defenders, fullbacks, or those players in more offensive positions. This is supported by wellestablished research that midfield players cover more total and high-intensity running than central defenders (Bradley et al., 2013; Gregson, Drust, Atkinson \& Di Salvo, 2010) and is 
consistent with cross-sectional studies conducted amongst elite-youth populations (Deprez et al., 2015).

The inclusion of acceleration instead of stamina for fullbacks may be indicative of modern styles of play where fullbacks require explosiveness to pass an opponent in wide areas of the pitch. Diverse speed abilities such as acceleration were considered important antecedents for fullbacks and players with attacking roles. This appears to be supported by a recent study where elite youth fullbacks and wide midfield recorded superior sprint times across $10 \mathrm{~m}$ and $20 \mathrm{~m}$ when compared to other outfield positions (Towlson et al., 2017).

A recent systematic review of the physiological and physical characteristics in youth soccer also confirmed the relevance of these performance indicators (Murr, Raabe, \& Höner, 2018). Similarly, motor skills such as agility and the ability to change direction is also well established in the literature (Murr, Raabe, \& Höner, 2018), however, it is worth noting that agility can be considered a speed-related motor ability without cognitive loads (Young, Dawson, \& Henry, 2015). Our e-Delphi poll and online survey however was not sensitive enough to distinguish the potential differences between agility and change-of-direction, therefore the term motor ability may be a more intuitive term.

Despite the stated importance of power in soccer (i.e. Boone et al., 2012) this physiological attribute was not recorded in the final list or included on the survey. This omission is not easily explained, however, power was recently reported to only contain small prognostic relevance as a performance indicator (Murr, Raabe, \& Höner, 2018) although the authors did provide a footnote stating that power can also be regarded as a component of speed and, therefore, should not be totally discounted. Anthropometric and physical performance attributes which have featured in previous talent research (i.e. body mass, body height, maturation and chronological age) were not accepted into the final list. This may be due to a body of well-established research suggesting that biological maturity temporarily affected 
387

388

389

390

391

392

393

394

395

396

397

398

399

400

401

402

403

404

405

406

407

408

409

410

several attributes, which makes these attributes not a stable predictor of future performance (Bidaurrazaga-Letona et al., 2015; Vandendriessche, et al., 2012).

\section{Limitations}

Despite making a novel contribution to the sport, exercise, and pedagogy literature this study contains a number of methodological limitations which need to be acknowledged. Firstly, consensus methods such as e-Delphi may contain bias in the recruitment of participants or participants may be obliged to vote in a certain way to pacify the group. The selection of panel members is considered to be the most important stage in the Delphi process (Hsu, 2007), as it relates to the quality of the eventual data capture. Despite our best efforts to recruit participants who were appropriately qualified and had experiences and knowledge of talent recruitment, we acknowledge that our completely male panel, who were all residents of the same country may be biased towards a national, rather than international context. Future studies should, therefore, consider including more international participants as well as female members. Another consideration may be the inclusion of players: as key stakeholders in this process, their input into the criteria selection would be beneficial as issues of vocabulary and definition might vary between scouts, coaches, and players. Secondly, the sample size of the online survey was modest, with the majority of those completing the survey listed as coaches, and it was not clear how many of these coaches had responsibility for player recruitment. Thirdly, the playerposition attributes are reported as isolated, discrete statements and a further suggestion is whether these attributes can occur in combination.

In order to verify the veracity of some of our claims, we propose that future research considers capturing verbal cognitions of talent scouts using real game footage. As talent identification processes are often undertaken away from the professional academy 
411 environment, this may help support coaches, teachers, and scouts identify potentially talented

412 players as a grading system could be added to each of the positional components.

413

\section{Conclusion}

415 Talent identification in youth soccer continues to operate with a limited number of objective 416 measures or consensus surrounding generic player-positional attributes. Thus, the purpose of 417 this study was to provide real-world information surrounding player-positional attributes 418 which, in-turn, could help inform youth talent selection programs for both coaches and 419 recruitment staff. The findings include some initial evidence that player-positional attributes 420 considered important at the junior-elite phase are more perceptual-cognitive and technical than 421 physiological or anthropometric. Despite 'hidden' attributes (e.g. coachability, flair, versatility, 422 vision etc) finding consensus in the e-Delphi poll, there was no evidence to support these traits 423 when associated with a specific playing position.

424

425 Acknowledgements

426 The authors would like to thank the panel members and the soccer coaches and recruitment 427 staff who participated in this exploratory study. 


\section{References}

430 Anderson G, Miller R. 2012. The academy system in English professional football. Liverpool, 431 Liverpool University Management School.

432

433 Baker J, Schorer J, Wattie N. 2017. Compromising Talent: Issues in Identifying and Selecting 434 Talent in Sport. Quest. iFirst:1-16. doi:10.1080/00336297.2017.1333438.

435

436

Bidaurrazaga-Letona I, Lekue JA, Amado M, Santos-Concejero J, Gil SM. 2015. Identifying 437 talented young soccer players: conditional, anthropometrical and physiological characteristics 438 as predictors of performance. Rev Int Cienc Deporte. 11(39):79-95. doi:10.5232/ricyde2015.03906.

440

441 Boone J, Vaeyens R, Steyaert A, Bossche L Vanden, Bourgois J. 2012. Physical Fitness of 442 Elite Belgian Soccer Players by Player Position. J Strength Cond Res. 26(8):2051-2057. 443 doi:10.1519/JSC.0b013e318239f84f.

444

445 Bradley PS, Lago-Peñas C, Rey E, Gomez Diaz A. 2013. The effect of high and low percentage 446 ball possession on physical and technical profiles in English FA Premier League soccer 447 matches. J Sports Sci. 31(12):1261-1270. doi:10.1080/02640414.2013.786185.Carling 448

449 Christensen MK. 2009. "An Eye for Talent": Talent Identification and the "Practical Sense” of 450 Top-level Soccer Coaches. Sociol Sport J. 26(3):365-382. 
452 Coelho e Silva MJ, Figueiredo AJ, Simões F, Seabra A, Natal A, Vaeyens R, Philippaerts R, 453 Cumming SP, Malina RM. 2010. Discrimination of U-14 Soccer Players by Level and Position. 454 Int J Sports Med. 31(11):790-796. doi:10.1055/s-0030-1263139.Coutinho P,

456 Collins D. 2014. Comment on "Football-specific fitness testing: adding value or confirming 457 the evidence?”J Sports Sci. 32(13):1206-1208. doi:10.1080/02640414.2014.898858.

458

459

Collins D, MacNamara A, Cruickshank A. 2018. Research and practice in talent identification 460 and development - some thoughts on the state of play. J Appl Sport Psychol. 0: 1-12.

461

462

Deprez D, Fransen J, Boone J, Lenoir M, Philippaerts R, Vaeyens R. 2015. Characteristics of 463 high-level youth soccer players: variation by playing position. J Sports Sci. 33(3): 243-254

464 doi: $\underline{10.1080 / 02640414.2014 .934707}$

465

466

Elferink-Gemser MT, Visscher C, Lemmink KAPM, Mulder T. 2007. Multidimensional 467 performance characteristics and standard of performance in talented youth field hockey 468 players: A longitudinal study. J Sports Sci. 25(4):481-489. doi:10.1080/02640410600719945. 469

470 Enright K, Morton J, Iga J, Lothian D, Roberts S, Drust B. 2018. Reliability of “in-season” 471 fitness assessments in youth elite soccer players: a working model for practitioners and 472 coaches. Sci Med Footb. 2(3):177-183. doi:10.1080/24733938.2017.1411603.

473

474 Fenner JSJ, Iga J, Unnithan V. 2016. The evaluation of small-sided games as a talent 475 identification tool in highly trained prepubertal soccer players. J Sports Sci. 34(20):1983-1990. 476 doi:10.1080/02640414.2016.1149602. 
478 Fernandez-Navarro J, Fradua L, Zubillaga A, Ford PR, McRobert AP. 2016. Attacking and 479 defensive styles of play in soccer: analysis of Spanish and English elite teams. J Sports Sci. 480 34(24):2195-2204. doi:10.1080/02640414.2016.1169309.

481

482 Ford PR, Yates I, Williams AM. 2010. An analysis of practice activities and instructional 483 behaviours used by youth soccer coaches during practice: Exploring the link between science and application. J Sports Sci. 28(5):483-495. doi:10.1080/02640410903582750.

485

Gil SM, Zabala-Lili J, Bidaurrazaga-Letona I, Aduna B, Lekue JA, Santos-Concejero J, 487 Granados C. 2014. Talent identification and selection process of outfield players and 488 goalkeepers in a professional soccer club. J Sports Sci. 32(20):1931-1939. 489 doi:10.1080/02640414.2014.964290.

490

Gregson W, Drust B, Atkinson G, Salvo V. 2010. Match-to-Match Variability of High-Speed 492 Activities in Premier League Soccer. Int J Sports Med. 31(04):237-242. doi:10.1055/s-0030493 1247546.

494

495

Gréhaigne J-F, Richard J-F, Griffin LL. 2005. Teaching and Learning Team Sports and Games. 496 Abingdon, Oxon: Routledge.

497

498 Haugaasen M, Toering T, Jordet G. 2014. From childhood to senior professional football: A 499 multi-level approach to elite youth football players' engagement in football-specific activities. 500 Psychol Sport Exerc. 15(4):336-344. doi:10.1016/j.psychsport.2014.02.007. 
502 Helmer-Hirschberg O. 1963. An experimental application of the Delphi method to the use of experts. Manage Sci. 9(3):458-467.

504

505 Hohmann T, Obelöer H, Schlapkohl N, Raab M. 2016. Does training with 3D videos improve 506 decision-making in team invasion sports? J Sports Sci. 34(8):746-755. 507 doi:10.1080/02640414.2015.1069380.

508

509

Hsu C-C, Sandford BA. 2007. The Delphi Technique: Making Sense Of Consensus. Pract

$510 \quad$ Assess Res Eval. 12(10):1-8.

511

512 Lago-Ballesteros J, Lago-Peñas C, Rey E. 2012. The effect of playing tactics and situational variables on achieving score-box possessions in a professional soccer team. J Sports Sci. 30(14):1455-1461. doi:10.1080/02640414.2012.712715.

515

516 Lago C. 2009. The influence of match location, quality of opposition, and match status on 517 possession strategies in professional association football. J Sports Sci. 27(13):1463-1469. doi:10.1080/02640410903131681.

520 Lago C, Martín R. 2007. Determinants of possession of the ball in soccer. J Sports Sci. 25(9):969-974. doi:10.1080/02640410600944626.

522

523 Larkin P, O'Connor D. 2017. Talent identification and recruitment in youth soccer: Recruiter's 524 perceptions of the key attributes for player recruitment. Sampaio J, editor. PLoS One. 525 12(4):e0175716. doi:10.1371/journal.pone.0175716. 
527 Larkin P, Reeves MJ. 2018 Jan 31. Junior-elite football: time to re-position talent 528 identification? Soccer Soc.:1-10. doi:10.1080/14660970.2018.1432389.

530 Le Moal E, Rue O, Ajmol A, Abderrahman AB, Hammami MA, Ounis OB, Kebsi W, Zouhal 531 H. 2014. Validation of the Loughborough Soccer Passing Test in Young Soccer Players. J

532 Strength Cond Res. 28(5):1418-1426. doi:10.1519/jsc.0000000000000296.

534 Leyhr D, Kelava A, Raabe J, Höner O. 2018. Longitudinal motor performance development in 535 early adolescence and its relationship to adult success: An 8-year prospective study of highly 536 talented soccer players. Plos ONE. 13(5):1-16.

537

538 Lewis CJ, McRobert AP, Reeves MJ, Roberts SJ. In Review. Using a verbal reporting technique to establish talent scout cognitions during formal competition. High Abil Stud.

Malina, RM. 2008. Biocultural factors in developing physical activity levels. In Smith, AL \& Biddle, SJH (Eds), Youth Physical Activity and Inactivity (pp. 141-166). Champaign, IL: Human Kinetics.

McRobert AP, Ward P, Eccles DW, Williams AM. 2011. The effect of manipulating contextspecific information on perceptual-cognitive processes during a simulated anticipation task. $\mathrm{Br}$ J Psychol. 102(3):519-534. doi:10.1111/j.2044-8295.2010.02013.x. Using an e-Delphi technique in achieving consensus across disciplines for developing best 551 practice in day surgery in Ireland. J Hosp Adm. 3(4). doi:10.5430/jha.v3n4p1. 
553 Meylan C, Cronin J, Oliver J, Hughes M. 2010. Talent Identification in Soccer: The Role of

554 Maturity Status on Physical, Physiological and Technical Characteristics. Int J Sport Sci Coach. 555 5(4):571-592.

556

557 Mesquita I, Fonseca AM. 2016. Talent development in sport: A critical review of pathways to 558 expert performance. Int J Sports Sci Coach. 11(2):279-293. doi:10.1177/1747954116637499.Dalkey

560

561 Murr D, Raabe J, Höner O. 2018. The prognostic value of physiological and physical 562 characteristics in youth soccer: A systematic review. Eur J Sport Sci. 18(1):62-74. 563 doi:10.1080/17461391.2017.1386719.

564

565 Nicholls SB, Worsfold PR. 2016. The observational analysis of elite coaches within youth

566 soccer: The importance of performance analysis. Int J Sports Sci Coach. 11(6):825-831. 567 doi:10.1177/1747954116676109.

568

569 O’Connor D, Larkin P, Mark Williams A. 2016. Talent identification and selection in elite 570 youth football: An Australian context. Eur J Sport Sci. 16(7):837-844. 571 doi:10.1080/17461391.2016.1151945.

572

573 Patterson JT, Lee TD. 2008. Organizing practice: the interaction of repetition and cognitive 574 effort for skilled performance. In: Farrow D, Baker J, McMahon C, editors. Developing Sports 575 Expertise: Researchers and Coaches Put Theory into Practice. Abingdon, Oxon: Routledge. p. $576 \quad 119-134$. 
578 Philippaerts RM, Vaeyens R, Janssens M, Van Renterghem B, Matthys D, Craen R, Bourgois

579 J, Vrijens J, Beunen G, Malina RM. 2006. The relationship between peak height velocity and 580 physical performance in youth soccer players. J Sports Sci. 24(3):221-230. 581 doi:10.1080/02640410500189371.

582

583 Raab M, Johnson JG. 2007. Expertise-based differences in search and option-generation 584 strategies. J Exp Psychol Appl. 13(3):158-170. doi:10.1037/1076-898X.13.3.158.

585

586 Reeves MJ, McRobert AP, Littlewood MA, Roberts SJ. 2018a. A scoping review of the 587 potential sociological predictors of talent in junior-elite football: 2000-2016. Soccer Soc. 588 doi:10.1080/14660970.2018.1432386.

589

590 Reeves MJ, Roberts SJ, McRobert AP, Littlewood MA. 2018b. Factors affecting the 591 identification of talented junior-elite footballers: a case study. Soccer Soc. 592 doi:10.1080/14660970.2018.1432383.

593

594 Roberts SJ. 2014. Talking relative age effects: a fictional analysis based on scientific evidence. 595 Asia-Pacific J Heal Sport Phys Educ. 5(1):55-66. doi:10.1080/18377122.2014.868290.

597 Roca A, Ford PR, McRobert AP, Mark Williams A. 2011. Identifying the processes 598 underpinning anticipation and decision-making in a dynamic time-constrained task. Cogn 599 Process. 12(3):301-310. doi:10.1007/s10339-011-0392-1. 
601 Roca A, Williams AM, Ford PR. 2012. Developmental activities and the acquisition of superior

602 anticipation and decision making in soccer players. J Sports Sci. 30(15):1643-1652.

603 doi:10.1080/02640414.2012.701761.

604

605 Savelsbergh GJP, Van Gastel PJ, Van Kampen PM. 2010. Anticipation of penalty kicking 606 direction can be improved by directing attention through perceptual learning. Int J Sport 607 Psychol. 41(1):24-41.

608

609 Tears C, Chesterton P, Wijnbergen M. 2018. The elite player performance plan: the impact of 610 a new national youth development strategy on injury characteristics in a premier league football 611 academy. J Sports Sci. 36(19):2181-2188. doi:10.1080/02640414.2018.1443746.

612

613 Towlson C, Cobley S, Midgley A, Garrett A, Parkin G, Lovell, R. 2017. Relative age, 614 maturation, and physical biases on position allocation in elite-youth soccer. Int J Sports Med. 615 38(3):201-209.

616

617 Unnithan V, White J, Georgiou A, Iga J, Drust B. 2012. Talent identification in youth soccer. 618 J Sports Sci. 30(15):1719-1726. doi:10.1080/02640414.2012.731515.

619

620 Vaeyens R, Lenoir M, Williams AM, Mazyn L, Philippaerts RM. 2007. The Effects of Task 621 Constraints on Visual Search Behavior and Decision-Making Skill in Youth Soccer Players. J 622 Sport Exerc Psychol. 29(2):147-169. doi:10.1123/jsep.29.2.147.

623 
624 Vaeyens R, Lenoir M, Williams AM, Philippaerts RM. 2007. Mechanisms Underpinning 625 Successful Decision Making in Skilled Youth Soccer Players: An Analysis of Visual Search 626 Behaviors. J Mot Behav. 39(5):395-408. doi:10.3200/JMBR.39.5.395-408.

627

628 Vaeyens R, Lenoir M, Williams AM, Philippaerts RM. 2008. Talent identification and 629 development programmes in sport: Current models and future directions. Sport Med. $630 \quad 38(9): 703-714$.

631

632 Vaeyens R, Malina RM, Janssens M, Van Renterghem B, Bourgois J, Vrijens J, Philippaerts 633 RM. 2006. A multidisciplinary selection model for youth soccer: the Ghent Youth Soccer 634 Project. Br J Sports Med. 40(11):928-934. doi:10.1136/bjsm.2006.029652.

635

636 Vandendriessche JB, Vaeyens R, Vandorpe B, Lenoir M, Lefevre J, Philippaerts RM. 2012. 637 Biological maturation, morphology, fitness, and motor coordination as part of a selection 638 strategy in the search for international youth soccer players (age 15-16 years). J Sports Sci. 639 30(15):1695-1703. doi:10.1080/02640414.2011.652654.

640

641 Vilar L, Araújo D, Davids K, Correia V, Esteves PT. 2013. Spatial-temporal constraints on 642 decision-making during shooting performance in the team sport of futsal. J Sports Sci. 643 31(8):840-846. doi:10.1080/02640414.2012.753155.

644

645 Vrljic K, Mallett CJ. 2008. Coaching Knowledge in Identifying Football Talent. Int J Coach 646 Sci. 2(1):63-81.

647 
648 Williams AM, Ford PR. 2009. Promoting a skills-based agenda in Olympic sports: The role of 649 skill-acquisition $\quad$ specialists. J $\quad$ Sports $\quad$ Sci. $\quad$ 27(13):1381-1392. 650 doi:10.1080/02640410902874737.

651

652 Williams AM, Ford PR. 2013. "Game intelligence": anticipation and decision making. In:

653 Williams AM, editor. Science and Soccer: Developing Elite Performers. 3rd ed. Abingdon, 654 Oxon: Routledge. p. 103-138.

655

656

657

658

659

660

661

662

663

664

665

666

667

668

669

670

671

672 
Table 1. Frequency of responses to attributes for 'Full-Back' position.

674

675

\begin{tabular}{|c|c|c|c|c|c|c|c|c|}
\hline \multirow[t]{2}{*}{ Attribute } & \multicolumn{7}{|c|}{ Ranking } & Mean \\
\hline & 1 & 2 & 3 & 4 & 5 & 6 & 7 & \\
\hline Tackling & 0 & 0 & 0 & 6 & 4 & 21 & 22 & 6.1 \\
\hline
\end{tabular}

676 
Table 2: Final list of agreed player attributes resulting from e-Delphi poll

\begin{tabular}{|c|c|c|c|}
\hline Physical & Psychological & Technical & Hidden \\
\hline Acceleration & Aggression & First touch & Adaptability \\
\hline Agility & Anticipation & Crossing & Consistency \\
\hline Balance & Bravery & Corners (delivering) & Versatility \\
\hline Fitness & Composure & $\begin{array}{l}\text { Dribbling/running with } \\
\text { the ball }\end{array}$ & Important matches \\
\hline Speed & Concentration & Finishing & Coachability \\
\hline Stamina & Decision-making & Free-kicks (delivering) & Communication \\
\hline Strength & Determination & Heading & Flair \\
\hline \multirow[t]{8}{*}{ Jumping reach } & Leadership & Long-range shooting & Creativity \\
\hline & Off-the-ball thinking & Long throw-ins & \\
\hline & Positioning & Passing accuracy & \\
\hline & Team work & Marking & \\
\hline & Attitude & Penalty taking & \\
\hline & Vision & Tackling & \\
\hline & & $1 \mathrm{v} 1$ & \\
\hline & & $\begin{array}{l}\text { Technique under } \\
\text { pressure }\end{array}$ & \\
\hline
\end{tabular}


Figure 1. E-Delphi process and results

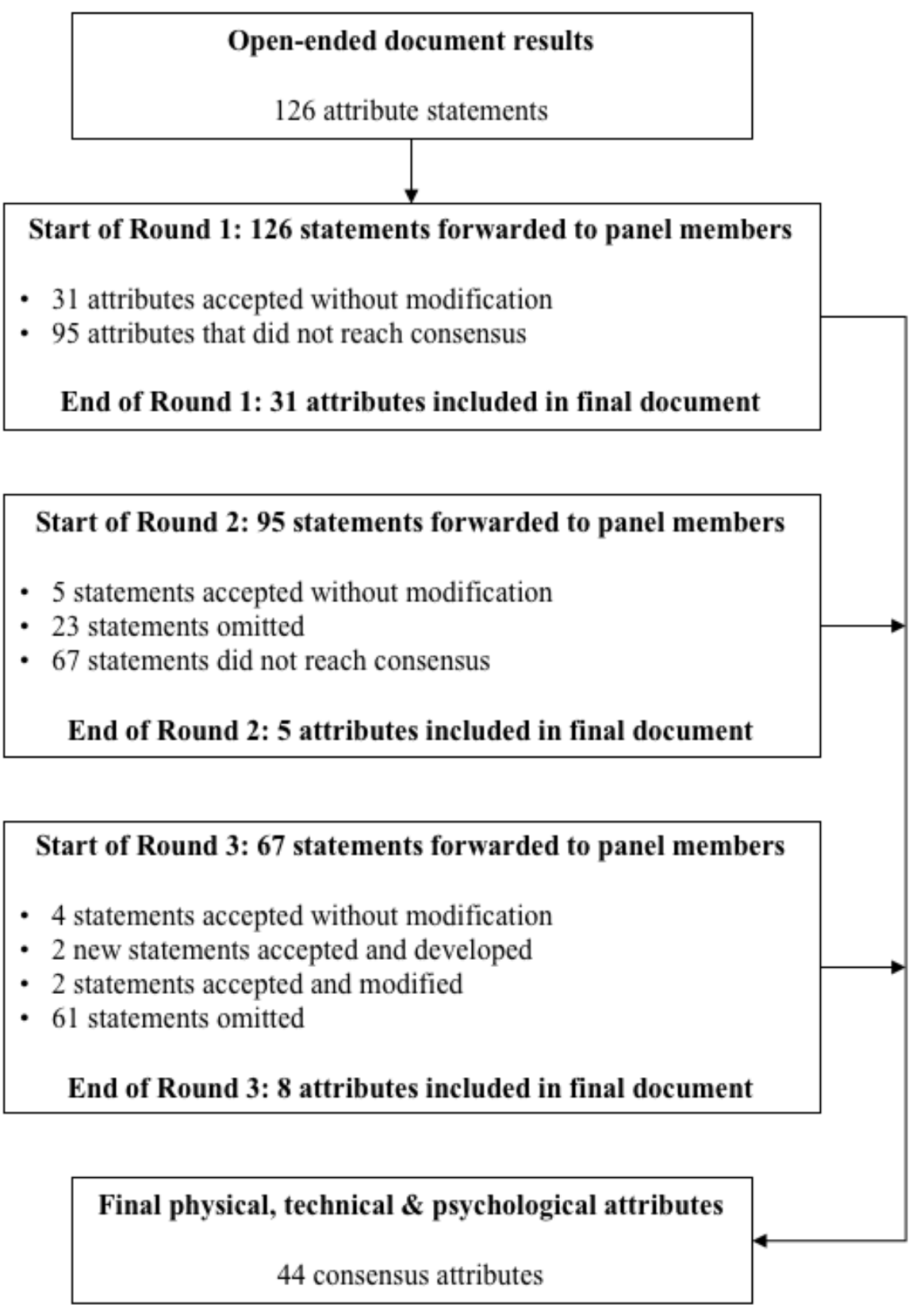




\begin{tabular}{|c|c|c|c|}
\hline Player Position & Attribute & Mean score & SD \\
\hline \multirow[t]{6}{*}{ Central Defender } & Decision making & 5.21 & 0.64 \\
\hline & Heading & 5.01 & 0.69 \\
\hline & Marking & 4.84 & 1.71 \\
\hline & Positioning & 3.83 & 1.61 \\
\hline & First touch & 3.63 & 1.13 \\
\hline & Strength & 3.32 & 0.52 \\
\hline \multirow[t]{6}{*}{ Full-back (Left/Right) } & Tackling & 6.11 & 0.51 \\
\hline & Crossing & 5.67 & 2.72 \\
\hline & Passing accuracy & 5.53 & 1.66 \\
\hline & Agility & 3.13 & 2.08 \\
\hline & First touch & 2.94 & 2.28 \\
\hline & Acceleration & 2.93 & 1.13 \\
\hline \multirow[t]{6}{*}{ Central Midfield } & Decision-making & 5.82 & 1.10 \\
\hline & $\begin{array}{l}\text { Technique under } \\
\text { pressure }\end{array}$ & 5.71 & 1.00 \\
\hline & Passing accuracy & 4.56 & 1.79 \\
\hline & Positioning & 3.94 & 1.72 \\
\hline & First touch & 3.73 & 1.91 \\
\hline & Stamina & 3.13 & 2.24 \\
\hline \multirow[t]{6}{*}{ Midfield (Left/Right) } & Decision-making & 6.14 & 2.16 \\
\hline & $\begin{array}{l}\text { Technique under } \\
\text { pressure }\end{array}$ & 5.28 & 1.05 \\
\hline & Crossing & 5.14 & 1.14 \\
\hline & Dribbling & 4.14 & 1.05 \\
\hline & Agility & 4.12 & 1.06 \\
\hline & Stamina & 2.86 & 1.99 \\
\hline \multirow{3}{*}{$\begin{array}{c}\text { Central/Wide } \\
\text { Attacking }\end{array}$} & Anticipation & 5.64 & 1.82 \\
\hline & Shooting & 3.65 & 1.49 \\
\hline & Finishing & 3.23 & 1.74 \\
\hline
\end{tabular}


First touch

$1 \mathrm{v} 1$

Speed
3.14

3.18

3.01

1.66

2.64

Table 3. Mean scores of player attributes according to position 